\title{
Evaluación de la respuesta celular tardía al uso de vacunas autógenas de estafilococo
}

\section{Evaluation of the late cellular response to the use of autogenous staphylococcal vaccines}

\author{
Carlos Alberto Ulloa Benitez ${ }^{1 *}$ y Daniel Ramón Gutiérrez Rodríguez ${ }^{1}$ \\ ${ }^{1}$ Hospital Universitario Clínico Quirúrgico "General Calixto García" \\ *carlosulloabtz@gmail.com
}

DOI: https://doi.org/10.26871/killkana_salud.v3i2.520

\begin{abstract}
Resumen
Contexto: El mejor conocido y potente de los antiguos adyuvantes es el adyuvante completo de Freund, y en su composición incluye bacterias muertas que se utilizan para potenciar la producción de anticuerpos. Cuando se mezcla el antígeno con el adyuvante completo de Freund, y se inyecta por vía subcutánea o intradérmica, es posible obtener una notable potenciación de la producción de anticuerpos, de manera especial con antígenos proteicos. Objetivo: evaluar la respuesta celular tardía posterior al uso de vacunas bacterianas autógenas con estafilococos, desde enero del 2010 hasta el mes de diciembre del 2011. Procedimientos: fue un estudio observacional, longitudinal, prospectivo y cuasiexperimental, con la muestra no probabilística por criterios, la cual estuvo constituida por individuos mayores de 18 años previo consentimiento informado de los mismos a participar en el estudio, concluyéndose con 87 pacientes. Se tomaron en consideración criterios de exclusión, de inclusión y de salida. Se creó una mesa de trabajo donde previamente se discutió de forma coordinada el proceder a llevar a cabo durante el estudio, con un consenso sobre el orden de compilación de la información. A cada paciente, se le administraron vacunas de estafilococo según el aislado en el medio de cultivo; y se aplicó de carácter autógeno. Se cultivan por separado y se les provoca la muerte mediante purificación y estandarización a través del método de opalescencia de McFarland. El esquema de vacunación fue vía subcutánea. Conclusiones: los pacientes lograron una buena respuesta celular tardía con vacunas autógenas de estafilococo después del tratamiento, y no hubo relación entre la respuesta celular tardía y los diferentes grupos de edades, ni con el tiempo de evolución de la enfermedad.
\end{abstract}

Palabras clave: Autógena, respuesta celular tardía.

\begin{abstract}
Context: The best known and potent of the ancient adjuvants, is Freund's complete adjuvant; and in its composition, it includes dead bacteria, which are used to enhance antibody production. When the antigen is combined with Freund's complete adjuvant and injected subcutaneously or intradermally, it is possible to obtain a remarkable potentiation of antibody production, especially with protein antigens. Objective: To evaluate the late cellular response after the use of autogenous staphylococcal bacterial vaccines, from January 2010 to December 2011. Procedures: It was an observational, longitudinal, prospective, and quasi-experimental study, with the non-probabilistic sample by criteria, which was constituted by individuals over the age of 18 with prior informed consent to participate in the study, concluding with 87 patients. Exclusion, inclusion, and exit criteria were taken into consideration. A work commission was created where it was previously discussed, in a coordinated manner, to proceed to conduct during the study, reaching consensus on the order of information compilation. Each patient was dosed with staphylococcal vaccines according to the isolate in the culture medium, and it was applied autogenously. They are cultivated separately and are killed by purification and standardization through the McFarland opalescence method. The vaccination scheme was subcutaneous. Conclusions: the patients reached a good late cellular response with autogenous staphylococcal vaccines after treatment, and there was not a relationship between the late cellular response and the different age groups, nor with the time of disease evolution.
\end{abstract}

Keywords: Autogenous, late cellular response.

\section{Introducción}

El mejor conocido y potente de los antiguos adyuvantes es el adyuvante completo de Freund, y en su composición incluye bacterias muertas que se utilizan para potenciar la producción de anticuerpos. Cuando se mezcla el antígeno con el adyuvante completo de Freund y se inyecta por vía subcutánea o intradérmica, es posible obtener una 
notable potenciación de la producción de anticuerpos, de manera especial con antígenos proteicos. Este conjunto de problemas ha obligado una vez más a la reconsideración y a la búsqueda de agentes dotados de inmunopotenciación, entre los cuales, aunque en pañales todavía, se pueden citar los que aumentan la actividad de macrófagos; y otros que mejoran la respuesta de células T; y que aumentan la respuesta de células. Sin embargo, existen otros que aumentan la actividad del complemento, y común para todas estas respuestas está el adyuvante completo de Freund. ${ }^{1}$ Muchos patógenos secretan componentes que disminuyen o desvían la respuesta inmunitaria del huésped. Algunas bacterias forman biopelículas para protegerse de las células y proteínas del sistema inmunitario. ${ }^{2}$ Las endotoxinas bacterianas son lipopolisacáridos complejos de las paredes celulares de bacterias gramnegativas. Los polisacáridos son antigénicos, y el polisacárido específico $(\mathrm{O})$ aporta a la molécula la mayor especificidad antigénica. El lípido A es el responsable de todos los demás efectos biológicos de la endotoxina, incluidos la toxina principal, los efectos mitogénicos y los adyuvantes. ${ }^{1}$ La infección de la piel es la más común de todas las infecciones bacterianas en el hombre. Las cepas de estafilococo que tienen cápsula, generan anticuerpos protectores, pero estas cepas no son patógenas. Solo el número y capacidad funcional de los granulocitos polimorfonucleares neutrófilos (PMN) es de importancia crítica en la defensa contra esta bacteria, siendo la línea primaria de defensa, que fagocitan y digieren las bacterias en los estadios más tempranos de la infección. ${ }^{3}$

La infección estafilocóccica es bastante común y de larga historia, pues es resistente a la penicilina, y con esto se ha vuelto un importante reto para la comunidad médica. ${ }^{4}$ Este germen coloniza a la mayoría de los recién nacidos en la primera semana de vida, y un 20-30\% de las personas normales son portadores que anidan siempre en las ventanas nasales. La transmisión se produce por lo general, mediante contacto directo o al diseminarse partículas densas hasta una distancia de 1.80 metros o menos. Los individuos muy contaminados y los portadores perianales son los que más diseminan la infección. ${ }^{5}$

Ahora bien, la respuesta coordinada de todos los elementos del sistema inmune (SI) frente a antígenos infecciosos constituye la respuesta inmune. La infección de la piel por estafilococo es la más común de todas las infecciones bacterianas en el hombre. Por tanto, los autores consideran que las formulaciones basadas en la combinación de alérgenos y protollin son tratamientos candidatos para el asma alérgica. Finalmente se han utilizados moléculas de Bordetella pertusis y toxinas de Vibrio cholerae en modelos experimentales, demostrando una importante capacidad de inducir una respuesta Th1 e incluso Tr1. ${ }^{6}$

\section{Problema científico}

Se desconoce la evaluación de la respuesta celular tardía posterior al uso de vacunas bacterianas autógenas con estafilococos.

\section{Objetivos}

1) Evaluar los pacientes según la respuesta celular tardía con vacunas autógenas de Estafilococo antes y después del tratamiento.

2) Establecer la posible relación entre la respuesta celular tardía con vacunas autógenas de Estafilococo al corte de los seis meses de tratamiento, y los diferentes grupos de edades.

3) Establecer la posible relación entre la respuesta celular tardía con vacunas autógenas de Estafilococo al corte de los seis meses de tratamiento, y el tiempo de evolución de la enfermedad.

\section{Diseño Metodológico}

Estudio observacional, longitudinal, prospectivo y cuasiexperimental, con el objetivo de evaluar de la respuesta celular tardía posterior al uso de vacunas bacterianas autógenas con estafilococos posterior al uso de vacunas bacterianas autógenas con estafilococos, desde enero del 2010 hasta el mes de diciembre del 2011.

- Selección del universo

El universo de trabajo estuvo comprendido por toda la población, con diagnóstico bacteriológico de portadores de estafilococo independientemente de la localización y el subtipo, que asistieron a consulta.

\section{- Muestreo}

La muestra no probabilística, por criterios, estuvo constituida por aquellos individuos mayores de 18 años que asistieron a la consulta de Alergología. Concluyéndose con 87 pacientes.

Se tomaron en consideración criterios de exclusión, de inclusión y de salida.

- Criterios de inclusión

Pacientes mayores de 18 años, previo consentimiento informado de los mismos.

Pacientes con enfermedades producidas por estafilococos independientemente del sero tipo identificado y del tiempo de evolución de la las lesiones.

Pacientes con cualquier factor de riesgo de padecer las afectaciones por estafilococos.

- Criterios de exclusión.

Paciente con historia de reacciones anafilácticas a cualquiera de los componentes de la vacuna previos al tratamiento en un término de doce semanas.

Pacientes que hayan recibido terapia antibiótica en los tres meses previos al estudio.

Embarazo, lactancia o puerperio.

Pacientes que manifiestan no tener condiciones para llevar a cabo el tratamiento, o no tengan posibilidad de asistir regularmente a las consultas para su seguimiento.

Retrasados mentales y/o alteraciones psiquiátricas que no cooperen con el tratamiento con la vacuna autógena.

Pacientes que presenten procesos neoformativos independientemente del tipo.

Negados a participar en el estudio. 
Pacientes que no presenten procesos sépticos agudos o en estados graves en curso, independientemente de la enfermedad estudiada.

- Criterios de salida

Pacientes que abandonen el estudio independientemente de la causa.

Pacientes que presenten alguna reacción adversa a la vacuna.

Muerte del paciente por causa ajena a la enfermedad de estudio.

- Diseño general de estudio.

Se creó una mesa de trabajo donde previamente se discutió de forma coordinada, el proceder con los pacientes, para así evitar pérdida de los mismos, llegando a consenso sobre el orden de compilación de la información.

El trabajo se realizó en etapas sucesivas para lograr una mejor organización del mismo.

Etapa I de selección: Durante esta etapa se procedió a la selección de la muestra revisándose todas las historias de salud individual definir los pacientes que participarían en el estudio, identificándose según los criterios de asignación muestral establecidos para el estudio.

Etapa II de identificación: Durante la misma se procedió a la indicación de la pruebas de respuesta tardía. Esta prueba consiste en introducir en la región intradérmica con una jeringuilla para prueba de tuberculina, una pequeña cantidad de alergeno a estudiar. Se indicó también un leucograma con el objetivo de precisar el conteo global de neutrófilos.

\section{Procedimiento de la práctica}

Se desinfecta la piel del paciente con agua jabonosa y alcohol etílico al $70 \%$ o isopropil-alcohol, se seca con algodón esterilizado y seco, después se practica preferentemente en la piel del brazo, cara externa, o antebrazo y se inyecta entre las capas de la piel una cantidad del extracto alergénico a probar de (0.01) 1 décima. Se utiliza para ello jeringuilla de tuberculina de $1 \mathrm{ml}$ y aguja de 26 ó 27 de bisel corto esterilizadas por autoclave, colocadas en orden en una bandeja de acero inoxidable. Se practica la inyección con el bisel hacia la piel y se introduce el extracto alergénico a probar.

\section{Extractos alergénicos a probar}

- Pool de bacterianas Respiratorias.

- Neiseria

- Klepsiella nemoneae

- Pseudomona auriginosa

- Pseudomona catarralis

- Neumococo

- Acinetobacter

- Toxoide Tetánico.

- Estreptococo del tipo alfa

- Estafilococo coagulasa positivo y negativo
LECTURA: Su interpretación se basa, no en la roncha, eritema o seudópodo sino en el nódulo ó induración que se produce. La medición se realizó con regla transparente milimetrada, obteniéndose cualquiera de las siguientes interpretaciones.

$$
\begin{gathered}
0 \mathrm{mms} \\
1-4 \mathrm{mms} \\
5-10 \mathrm{mms} \\
>10 \mathrm{mms}
\end{gathered}
$$

Etapa III de Inmunoterapia: A cada paciente, se le administró vacunas de estafilococo según el aislado en el medio de cultivo; y se aplicó de carácter autógeno. Se cultivan por separado y se les provoca la muerte mediante purificación y estandarización a través del método de opalescencia de McFarland, comenzando con una concentración bacteriana de 250000000 para el primer frasco, 500000000 para el segundo frasco y 1000000000 para el tercer frasco y la dosis de mantenimiento. Vía de administración: Subcutánea

Técnica: Se administró con jeringuillas de tuberculinas y agujas hipodérmicas 26 o 27, en la región latero-posterior del brazo a un ángulo de 450, previamente desinfectada la zona con alcohol de $70^{\circ}$

Comenzar con $0.1 \mathrm{ml}$ e ir incrementando $0.1 \mathrm{ml}$ cada día de vacunación hasta llegar a la dosis de $0.9 \mathrm{ml}$. Continuar con esta cantidad dos veces por semana hasta terminar frasco. La dosis de mantenimiento se mantuvo en $0.5 \mathrm{ml}$ con la misma frecuencia.

Se realizó una evaluación nuevamente el índice neutropénico así como la respuesta celular tardía, posterior a los seis meses de encontrarse en tratamiento de mantenimiento.

- Variable de eficacia utilizada para medir la respuesta celular tardía a la autovacuna con estafilococo.

La prueba cutánea de hipersensibilidad retardada, y el conteo absoluto de neutrófilos resultados emitidos en el leucograma emitido, antes del inicio del tratamiento como complementario y al período evaluativo subsiguiente a los seis meses. Se determinó por la fórmula siguiente:

Conteo absoluto de neutrófilos

$$
\frac{\text { Leucocitos Totales }}{10 \%}=\frac{X}{\text { neutrófilo s }}
$$

Resultado de respuesta inmunitaria competente Cuando el nódulo o induración que se produce alcanza valores de rango $5 \mathrm{mms}$ hasta $10 \mathrm{mms}$, con conteo global de neutrófilos de 1400 y más valores.

\section{Aspectos Bioéticos}

A partir de las regulaciones internacionales que se expone en la normativa legal (europea y española) que afecta a la fabricación de extractos alergénicos para inmunoterapia, donde se expone en el Real Decreto 288/1991, sobre medicamentos inmunológicos de uso humano, en el Artículo $1^{\circ}$ especifica que: 
Son medicamentos inmunológicos los sueros, las vacunas, las toxinas y los alérgenos, incluidas las vacunas individualizadas para un paciente específico.

\section{Se entenderá por:}

Alérgeno: Todo producto destinado a identificar o provocar una modificación específica y adquirida de la respuesta inmunológica a un agente alergizante.

Vacunas individualizadas: Son las preparadas con agentes inmunizantes, a concentración y dilución específica sobre la base de la correspondiente prescripción facultativa para un paciente determinado.

\section{En el Artículo $2^{\circ}$ describe que:}

Los medicamentos inmunológicos fabricados industrialmente tienen la consideración legal de especialidades farmacéuticas y, por tanto, están sometidos a autorización y registro en el Ministerio de Sanidad y Consumo y a las demás exigencias que la legislación vigente impone a esa clase de medicamentos.

Las vacunas individualizadas se regirán por lo dispuesto en el Artículo $8^{\circ}$ de este Real Decreto.

\section{En el Artículo 8 expone que:}

La elaboración, distribución y dispensación de las vacunas individualizadas sean antialérgicas, bacterianas o autovacunas, obedecerá a una prescripción médica para un paciente determinado.

Por lo que para el estudio se cumplieron con los principios bioéticos requeridos por los estudios en seres humanos. Se informó en la institución antes mencionada, sobre la realización del estudio, obteniéndose de la misma el consentimiento para llevar a cabo el trabajo investigativo, fue evaluado por el comité de ética de investigación el cual expuso el consentimiento para la ejecución del mismo. La investigación incluyó los requisitos de:

- Proteger a los sujetos de la investigación de posibles daños y preservar sus derechos.

- Se veló por los principios del consentimiento informado recogidos en la Declaración de Helsinki. Ningún sujeto fue obligado a participar en el estudio.

- Técnicas para el análisis de los datos

Subsiguiente los datos recolectados fueron introducidos en una base de datos computados, y procesados mediante el paquete estadístico "Statistical Package for Social Sciences" (SPSS), versión 15.0 para Windows, se les aplicó el método estadístico descriptivo, porcentual, y los métodos estadísticos inferenciales de la prueba no paramétrica del chi-cuadrado para determinar asociación de variables resumidos en tablas. Además se realizó el test de McNemar para dos variables dicotómicas relacionadas. Estimándose criterios de rango.

- $\quad$ Si $p<0,05$ la relación es significativa.

- $\quad$ Si $p>0,05$ no existe relación significativa.

\section{Discusión de los resultados}

Tabla 1. Distribución de frecuencias de pacientes según la respuesta celular tardía con vacunas autógenas de Estafilococo antes y después del tratamiento

\begin{tabular}{lcc}
\hline \multicolumn{3}{c}{ Respuesta celular tardía antes del tratamiento } \\
& Frecuencia & Porcentaje* \\
\hline $\begin{array}{l}\text { Sin respuesta de estimulación del sistema in- } \\
\text { mune }\end{array}$ & 79 & 90,8 \\
$\begin{array}{l}\text { Con respuesta de estimulación del sistema } \\
\text { inmune }\end{array}$ & 8 & 9,2 \\
\hline \multicolumn{3}{c}{ Respuesta celular tardía a los 6 meses de tratamiento } \\
$\begin{array}{l}\text { Sin respuesta de estimulación del sistema in- } \\
\text { mune }\end{array}$ & 17 & 19,5 \\
$\begin{array}{l}\text { Con respuesta de estimulación del sistema } \\
\text { inmune }\end{array}$ & 70 & 80,5 \\
\hline
\end{tabular}

Fuente: instrumento diseñado para el estudio.

Todos los porcentajes han sido calculados en base al total de pacientes $(\mathrm{n}=87)$

En la tabla 1 se expone la distribución de frecuencias de pacientes según la respuesta celular tardía con vacunas autógenas de Estafilococo, observándose que al terminar el tratamiento el $80,5 \%$ de los pacientes habían logrado una estimulación del sistema inmune, evaluado por más de cinco antígenos en la prueba de respuesta celular tardía.

Al evaluar la intervención de las vacunas autógenas sobre su efecto en sistema a través de la prueba del test de McNemar, se observó una asociación estadísticamente significativa de $(\mathrm{p}=0.00<0,05)$ infiriendo efectiva la intervención con las vacunas autógenas sobre el sistema inmune al corte de los seis meses de tratamiento.

Al observar la tabla se esgrime que los pacientes estudiados sin respuesta de estimulación del sistema inmune se ubicaron en un $90,8 \%$ al iniciar el tratamiento. Sin embargo el realizar el corte de los seis meses de tratamiento los que se encontraban sin respuesta de estimulación del sistema inmune se ubicó en un 19,5\%. Ahora bien, se plantea en la literatura que el desarrollo de una infección estafilocócica guarda relación con la resistencia del huésped a las infecciones, y con la virulencia del microorganismo. El riesgo de infección aumenta cuando esas barreras mucocutáneas son defectuosas debido a intervenciones quirúrgicas, traumatismos, cuerpos extraños y quemaduras. En un estudio realizado en el Hospital Pediátrico William Soler por los autores como Insua Arregui C, y Jauma Rojo A, plantearon que la administración de la vacuna estafilocóccica aplicada a los pacientes, a pesar de estar compuesta por bacterias muertas, estimuló ambos tipos de respuesta inmune: humoral y celular. Este fenómeno pudiera explicarse por el hecho de que al emplearse la bacteria muerta pero entera, se conservaran los componentes proteicos y polisacáridos del microorganismo, ejerciendo una acción similar a la que se logra con las llamadas vacunas conjugadas. Todo lo anterior parece indicar que la vacuna estafilocóccica puede constituir una terapia potente como inductora de la síntesis y liberación de citocinas del patrón TH1 o pro inflamatorias en la respuesta inmune adquirida, en especial en la producción de IFN- $\gamma$ en el individuo previamente 
sensibilizado por infecciones anteriores. Los resultados de evolución clínica favorable en estos pacientes coinciden con otros autores. Considerando que el efecto beneficioso de la utilización de vacunas bacterianas en los pacientes con recurrencia de piodermitis está relacionado con la acción específica de esta inmunomodulación sobre la inmunidad del enfermo, sugirieron los autores que la recuperación del sistema inmunológico en los pacientes pediátricos tratados con vacunas estafilocócicas de forma gradual y como único tratamiento, con historia de infecciones recurrentes, pudiera constituir un modelo terapéutico adyuvante para el sistema inmunológico. Concluyeron en su estudio los autores que la vacuna estafilocóccica estimuló la producción de IgG sérica y la proliferación de linfocitos $\mathrm{T}$ en pacientes con piodermitis recurrente y que la vacuna estafilocóccica no estimuló la producción de $\operatorname{IgA}$, IgM ni la activación de linfocitos $\mathrm{T}$ y que predominó la evolución clínica hacia la mejoría o curación de las lesiones después del tratamiento con la vacuna estafilocóccica. ${ }^{7}$

Tabla 2. Asociación de la respuesta celular tardía con vacunas autógenas de estafilococo al corte de los 6 meses de tratamiento y los diferentes grupos de edades

\begin{tabular}{|c|c|c|c|c|}
\hline \multirow{3}{*}{$\begin{array}{l}\text { GRUPOS DE } \\
\text { EDAD (en años) }\end{array}$} & \multicolumn{4}{|c|}{ Respuesta celular tardía a los 6 meses de tratamiento } \\
\hline & \multicolumn{2}{|c|}{ Sin respuesta } & \multicolumn{2}{|c|}{ Con respuesta } \\
\hline & No & $\%$ & No & $\%$ \\
\hline $18-29$ & 8 & 47 & 25 & 35,7 \\
\hline $30-39$ & 2 & 11,8 & 18 & 25,7 \\
\hline $40-49$ & - & & 19 & 27,2 \\
\hline 50 años y mayores & 7 & 41,2 & 8 & 11,4 \\
\hline
\end{tabular}

Fuente: instrumento diseñado para el estudio

Todos los porcentajes han sido calculados en base al total de pacientes $(\mathrm{n}=17)$

* Todos los porcentajes han sido calculados en base al total de pacientes $(\mathrm{n}=70)$

Estadístico exacto de Fisher $=2,243 \Longrightarrow p=0,879>0,05$

La tabla 2 muestra la asociación de la respuesta celular tardía con vacunas autógenas de estafilococo, al corte de los seis meses de tratamiento y los diferentes grupos de edades. Existiendo una asociación negativa y estadísticamente no significativa entre las variables de estudio, al realizar el estadístico exacto de Fisher con un valor de 2,243 para una $p=0,879>0,05$. En la observación de la tabla se muestran los porcentajes de la respuesta celular tardía al corte de los seis meses de tratamiento. Donde las edades que alcanzaron una mayor respuesta al tratamiento establecido fueron los grupos de edades 18 años hasta 29 años con un $35,7 \%$ y los de 40 años hasta 49 años con un $27,2 \%$.

En la literatura se expone que la inmunidad celular, función del linfocito T (LT) además de participar en importantes aspectos de la inmunorregulación, es indispensable en la resolución de infecciones intracelulares, principalmente virales y micóticas, y en la vigilancia inmunológica de las neoplasias malignas en cualquiera de las edades en que se evalúe. La inmunidad celular in vivo se evalúa a través de la respuesta de hipersensibilidad retardada. Una vez que el LT CD4(+) helper o inductor, reconoce a su antígeno específico y monta una respuesta primaria, es capaz de desarrollar memoria inmunológica, en forma paralela independientemente de la edad, aunque muchos autores plantean que el niño al nacer tiene un sistema inmune competente otros discrepan de esta teoría.

Al encontrar nuevamente al antígeno, el LT se activa y, a través de la producción de factores solubles, citoquinas, atrae al sitio a células efectoras, en especial monocitomacrófagos dando lugar a una respuesta inflamatoria que se traduce en infiltrado celular. Por lo tanto, la introducción de un antígeno intradérmico para el cual existen LT sensibilizados conduce a la instalación de una respuesta inflamatoria en el sitio de inoculación, caracterizado por induración, dada por el infiltrado celular, de carácter retardado, que comienza a las $6 \mathrm{~h}$, y alcanza un máximo entre las 24 y 72 h. ${ }^{8,9}$

En consideración con estos resultados, se puede plantear que los adultos mayores chilenos, sufren una disminución de su capacidad de respuesta de hipersensibilidad retardada cutánea, en relación a adultos jóvenes de la misma región y que es muy difícil lograrla con vacunas a partir de bacterias muertas o al menos no logran una estimulación permanente. El estudio de Jurlow y colaboradores demostró que en adultos jóvenes chilenos, la respuesta en cuanto a número de antígenos a los cuales respondieron los sujetos evaluados fue menor, al compararlos con población estadounidense. ${ }^{10}$ Esta falla en la respuesta global y particular a TBC debería transformarse en una alerta que se traduzca en una evaluación profunda y exhaustiva del individuo afectado, y en la corrección, cuando sea posible, de factores capaces de afectar la integridad del sistema inmune, como por ejemplo, las carencias nutricionales. (84)

En un estudio realizado en Canadá, se observó que la edad de los pacientes afecta la capacidad de respuesta del sistema inmune en pruebas de hipersensibilidad retardada cutánea de manera negativa, de modo que el número de individuos que responde a múltiples antígenos disminuye progresivamente al avanzar la edad. En el mismo estudio, se encontró una tasa de anergia (ausencia completa de respuesta en pruebas de hipersensibilidad retardada) similar para hombres y mujeres, de $8 \%$. Se observó que el promedio de respuesta en cuanto a número de antígenos cayó de 3,8 para el grupo de 25 a 40 años de edad, a 1,9 en individuos $>65$ años. A la vez, la sumatoria de diámetros de respuesta (considerando área indurada), se redujo de 13,9 $\mathrm{mm}$ para el grupo de 25 a 40 años, a $10,5 \mathrm{~mm}$ para el grupo de 41 a 65 años, y a 7,6 mm para los >65 años. El grupo recomienda no comparar los resultados de este tipo de pruebas entre diferentes localidades. ${ }^{9}$

Al comparar los resultados de las pruebas de hipersensibilidad retardada cutánea aplicadas a chilenos jóvenes y mayores, aparecen diferencias significativas en la capacidad de respuesta para antígeno tetánico y diftérico en mujeres, y para antígeno diftérico y proteus, en hombres, con ventajas para los adultos jóvenes. Sin embargo, es probable que se requiera extender este análisis a un número 
mayor de personas, para obtener un rango de respuesta normal de hipersensibilidad retardada cutánea, para el método descrito. $^{11}$

Tabla 3. Asociación de la respuesta celular tardía con vacunas autógenas de Estafilococo al corte de los 6 meses de tratamiento y el tiempo de evolución de la enfermedad

\begin{tabular}{lcccc}
\hline Tiempo de & \multicolumn{2}{c}{ Respuesta celular tardía a los 6 meses de tratamiento } \\
evolución de la & \multicolumn{2}{c}{ Sin respuesta } & \multicolumn{2}{c}{ Con respuesta } \\
enfermedad & No & $\%$ & No & $\%$ \\
\cline { 2 - 5 } Menos de 6 meses & 1 & $5,9 \%$ & 16 & $22,9 \%$ \\
6 meses y mas & 16 & $94,1 \%$ & 54 & $77,1 \%$ \\
\hline
\end{tabular}

Fuente: instrumento diseñado para el estudio

Todos los porcentajes han sido calculados en base al total de pacientes $(\mathrm{n}=17)$

* Todos los porcentajes han sido calculados en base al total de pacientes $(\mathrm{n}=70)$

Estadístico exacto de Fisher $=2,507 \Longrightarrow p=0,175>0,05$

La tabla 3 expone la asociación de la respuesta celular tardía con vacunas autógenas de estafilococo al corte de los 6 meses de tratamiento y el tiempo de evolución de la enfermedad. Al realizarse el Estadístico exacto de Fisher con valor de 2,507, con $p=0,175>0,05$ se deduce que el tiempo de evolución de la enfermedad no guarda relación con la respuesta celular tardía con vacunas autógenas de estafilococo al corte de los 6 meses de tratamiento.

Al observar los porcentajes expuestos en la tabla, los enfermos con una evaluación de la enfermedad de 6 meses y más, se mantuvieron sin respuesta celular tardía con la vacuna con estafilococo en un 94,1\%. En la literatura se expone que en un estudio, primero que se realiza en Cuba, en pacientes desnutridos y más de un año de padecimientos por enfermedad estafilocócicas recurrentes, la combinación de varios inmunomoduladores con gérmenes bacterianos logró una reducción significativa de la frecuencia y gravedad de las recurrencias infecciosas, principalmente con estafilococo y estreptococos. ${ }^{12}$

Chevalier estudió a un grupo de niños bolivianos, con lesiones dermatológicas ocasionadas por estafilococo de más de un año de evolución, y comprobó que la recuperación de los parámetros antropométricos se alcanzaba en unas cinco semanas; sin embargo, la recuperación inmune basada en: estudios de sub-poblaciones linfocitarias y ultrasonido de timo se lograba en nueve semanas. ${ }^{13}$

\section{Conclusiones}

Los pacientes lograron una buena respuesta celular tardía con vacunas autógenas de Estafilococo después del 10. tratamiento.

No hubo relación entre la respuesta celular tardía con vacunas autógenas de Estafilococo a los 6 meses de tratamiento y los diferentes grupos de edades.

No hubo relación entre la respuesta celular tardía con vacunas autógenas de Estafilococo a los 6 meses de tratamiento y el tiempo de evolución de la enfermedad.

\section{Fuente de Financiamiento}

Este estudio es autofinanciado

\section{Conflicto de Intereses}

No existen conflictos personales, profesionales, financieroso de otro tipo.

\section{Consentimiento Informado}

Los autores cuentan con el consentimiento informado de los paciente para la investigación, la publicación del caso y sus imágenes.

\section{Referencias Bibliográficas}

1. Alexander JW, Good RA. Principios de inmunología clínica. Reverté; 1980.

2. Housden N, Harrison S, Roberts S, Beckingham J, Graille M, Stura E, et al.. Immunoglobulin-binding domains: Protein L from Peptostreptococcus magnus. Portland Press Ltd.; 2003.

3. Hernández-Moreno VJ, Rodríguez-Vera C, MildesteinFarréz S, García-Díaz P, Cabrera-Llano J. Mecanismos inmunológicos y de escape en la infección por bacterias grampositivas: el estafilococo dorado. Papel de las vitaminas y los minerales. Rev Cubana Hematol Inmunol Hemoter [serie en Internet]. 2004;

4. Weller T. Methicillin-resistant Staphylococcus aureus typing methods: which should be the international standard? Journal of Hospital Infection. 2000;44(3):160-172.

5. Litman GW, Cannon JP, Dishaw LJ. Reconstructing immune phylogeny: new perspectives. Nature Reviews Immunology. 2005;5(11):866-879.

6. Lowy FD. Staphylococcus aureus infections. New England journal of medicine. 1998;339(8):520-532.

7. Insua Arregui C, Jauma Rojo AJ, Marsán Suárez V, Díaz Pérez C, González Labrada C. Evaluación clínica e inmunológica de niños con piodermitis recurrente tratados con la vacuna estafilococcica. Revista Habanera de Ciencias Médicas. 2009;8(2):0-0.

8. Kniker W, Anderson C, McBryde J, Roumiantzeff M, Lesourd B. Multitest CMI for standardized measurement of delayed cutaneous hypersensitivity and cellmediated immunity. Normal values and proposed scoring system for healthy adults in the USA. Annals of allergy. 1984;52(2):75-82.

9. Murgueytio P, Evans R. Delayed cutaneous hypersensitivity: multitest CMI reliability assessment in groups of volunteers. Annals of allergy. 1988;61(6):463-465.

10. Jurlow M, Orvieto S, Guerrero P, Bezanilla S, Cox S, Cartier C, et al. Hipersensibilidad retardada a antígenos de evocación: Valores normales en adultos jóvenes chilenos. Rev méd Chile. 1996;p. 61-9.

11. Quezada A, Anderson H, Pinto V, Rodríguez J. Prueba múltiple para inmunidad celular en niños con infecciones recurrentes. Revista chilena de pediatría. 1992;63(6):298303. 
12. Bardana Jr EJ. Recent developments in immunomodulatory therapy. Journal of allergy and clinical immunology. 1985;75(4):423-436.

13. Chevalier P, Sevilla R, Zalles L, Sejas E, Belmonte G, Parent G. Study of thymus and thymocytes in Bolivian preschool children during recovery from severe protein energy malnutrition. Journal of nutritional immunology (USA). 1994;

Recibido: 12 de febrero de 2019

Aceptado: 10 de julio de 2019 
